\title{
The Effect of Platelet-Rich Plasma on the Coronally Advanced Flap Root Coverage Procedure: A Pilot Human Trial
}

Lien-Hui Huang, ${ }^{*}$ Rodrigo E.F. Neiva, ${ }^{\dagger}$ Stephen E. Soehren,$^{\dagger}$ William V. Giannobile,$^{\dagger}$ and Hom-Lay Wang ${ }^{\dagger}$

Background: Coronally advanced flap (CAF) has been shown to effectively treat gingival recession. Platelet-rich plasma (PRP), containing autologous growth factors, has been shown to promote soft tissue healing. Therefore, the purpose of this study was to evaluate the effects of PRP in combination with CAF.

Methods: Twenty-four systemically healthy patients participated in this study. A single Miller's Class I buccal recession defect per patient was treated. These patients were randomly assigned into CAF or PRP + CAF groups. Clinical parameters included recession depth (RD), recession width (RW), gingival thickness (GT), width of keratinized tissue (WKT), clinical attachment level (CAL), probing depth (PD), plaque index (PI), wound healing index (WHI), and gingival index (GI). PRP was prepared from whole blood drawn prior to surgery and applied to root surfaces. Patients were followed at 2, 4, 12, and 24 weeks post-surgery.

Results: Twenty-three patients completed the study. The $\mathrm{RD}$ at 24 weeks was significantly reduced from $2.9 \pm 0.5$ to $0.5 \pm 0.6 \mathrm{~mm}$ in the CAF group $(P<0.05)$ and from $2.8 \pm 0.2$ to $0.5 \pm 0.7 \mathrm{~mm}$ in the PRP $+\mathrm{CAF}$ group $(P<0.05)$. The mean root coverage was $83.5 \% \pm 21.8 \%$ in the CAF group and $81.0 \% \pm 28.7 \%$ in the CAF + PRP group $(P>0.05)$. Fourteen out of 23 patients $(60.9 \%)$ experienced $100 \%$ root coverage at the 24-week postoperative follow-up.

Conclusion: Based on the results of this pilot study, the application of PRP in CAF root coverage procedure provides no clinically measurable enhancements on the final therapeutic outcomes of CAF in Miller's Class I recession defects. J Periodontol 2005;76:1768-1777.

\section{KEY WORDS}

Gingiva; gingival recession/surgery; gingival recession/ therapy; plasma; surgical flaps.

\footnotetext{
* Currently, private practice, Taipei, Taiwan; previously, Department of Periodontics/ Prevention/Geriatrics, University of Michigan, School of Dentistry, Ann Arbor, MI.

$\dagger$ Department of Periodontics/Prevention/Geriatrics, University of Michigan, School of Dentistry.
}

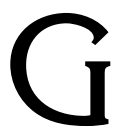
ingival recession is defined as the gingival margin located apical to the cemento-enamel junction (CEJ). ${ }^{1}$ The prevalence of gingival recession ranges from $20 \%$ to $100 \%$ in adults. $^{2-5}$ Gingival recession may result in dentinal hypersensitivity, ${ }^{6}$ pain, difficult oral hygiene, ${ }^{7}$ root caries, unaesthetic gingival appearance, and periodontal attachment loss. ${ }^{8}$ Therefore, root coverage procedures have been developed to treat these clinical conditions. Modalities of root coverage procedures include 1) laterally sliding flap ${ }^{9}$; 2) double papillae flap ${ }^{10}$; 3) coronally advanced flaps $\left.(\mathrm{CAF})^{11,12} ; 4\right)$ epithelialized gingival graft $^{13}$; 5) subepithelial connective tissue graft ${ }^{14}$; and 6) guided tissue regeneration (GTR)-based root coverage procedures. ${ }^{15}$ Coronally repositioned flaps were originally used to gain attachment on teeth with periodontal disease. ${ }^{11}$ They were later modified to repair gingival recession. ${ }^{16}$ The coronally repositioned flap is less technique sensitive than rotational flaps. It also eliminates the need to harvest donor tissue and minimizes the morbidity of donor areas. The term "coronally advanced flap" was coined by Pini-Prato et al. ${ }^{17}$ in 1999 to better reflect the procedure. CAF has been shown to predictably achieve root coverage. The average root coverage achieved with this technique ranges from $75 \%$ to $82.7 \%$, with $24 \%$ to $95 \%$ of sites achieving complete root coverage. ${ }^{18,19}$ Histologically, CAF resulted in the re-formation of epithelial and 
connective tissue attachment with minimal bone repair. ${ }^{20,21}$ Thereafter, various adjunctive agents have been applied to promote healing and further enhance clinical outcomes. These include root conditioners (e.g., citric acid 22,23 and tetracycline ${ }^{24}$ ), enamel matrix proteins, ${ }^{25-28}$ recombinant human growth factors, and platelet-rich plasma (PRP) ${ }^{29}$ PRP has become a focus of current studies due to its potential to accelerate wound healing. ${ }^{30,31}$

PRP is derived from concentrated platelets, allowing it to deliver a greater concentration of autologous growth factors including platelet-derived growth factor (PDGF), transforming growth factor beta (TGF- $\beta$ ), vascular endothelial growth factor (VEGF), insulin-like growth factor (IGF)-I, and epithelial growth factor (EGF). ${ }^{32-37}$ These native growth factors promote fundamental phases of tissue repair such as mitogenesis and angiogenesis. ${ }^{38}$ Moreover, PRP can be considered a safe method of growth factor utilization due to its autologous origin. Depending on the initial platelet counts, it is common to achieve platelet concentration three times higher than baseline. $34,35,39-41$

PRP was introduced to dentistry in 1998 by Marx et al. ${ }^{34}$ Marx stated that PRP should contain more than $1,000,000$ platelets/ $\mu$ l to effectively enhance wound healing. ${ }^{38}$ Many studies have demonstrated that PRP is able to enhance early graft maturity, bone density, and new bone formation in ridge preservation procedures, ${ }^{31,42}$ mandibular reconstruction, ${ }^{43}$ repair of peri-implant defects, ${ }^{44-47}$ and sinus augmentation. ${ }^{48-52}$ Although these studies examining PRP and its potential on bone healing showed encouraging results, limited evidence exists for its effects on soft tissue healing. So far, to our knowledge, only one case report has been published regarding the application of PRP with subepithelial connective tissue grafts or GTR root coverage procedures. ${ }^{29}$ It was found that PRP decreased postoperative bleeding, enhanced soft tissue healing, promoted initial stabilization and revascularization of the flaps and grafts, and reduced postoperative infection and graft sloughage. Hence, the purpose of this randomized, controlled pilot trial was to evaluate the role of PRP in CAF root coverage procedures.

\section{MATERIALS AND METHODS}

\section{Study Design}

This study was designed as a randomized, controlled, examiner-masked pilot clinical trial. The protocol was reviewed and approved by the University of Michigan Institutional Review Board (IRB). All subjects were required to read and sign an informed consent form explaining all study-related procedures before inclusion in the study. Twenty-four subjects were randomly assigned to either test (PRP + CAF) or control groups (CAF). Randomization was performed immediately prior to surgery by drawing envelopes including notes stating either "test" or "control." Presurgical procedures included oral hygiene instructions, full-mouth scaling and root planing, and occlusal adjustment as indicated. Surgical procedures as well as PRP preparations were performed by a single investigator. A masked and calibrated examiner collected and recorded the clinical parameters.

\section{Subject Recruitment}

From January 2, 2003 to February 28, 2004, 24 patients were recruited from the University of Michigan, School of Dentistry based on the following inclusion criteria: 1) systemically healthy subjects; 2) nonsmokers; 3) patients who were willing to comply with all study-related procedures; 4$) \geq 18$ years old; 5) ability to maintain good oral hygiene (O'Leary plaque score $^{53} \leq 20 \%$ ); 6) maxillary or mandibular incisors, canines, or premolars with Miller's Class I (confirmed by radiographic analysis of the involved tooth) facial gingival recession; ${ }^{54} 7$ ) gingival thickness (GT) $\geq 0.5$ $\mathrm{mm}$ as measured $2 \mathrm{~mm}$ apical to the gingival margin; 8 ) width of keratinized gingiva $\geq 2 \mathrm{~mm}$; and 9) recession depth $(\mathrm{RD}) \geq 2 \mathrm{~mm}$. The exclusion criteria was determined as follows: 1) previous surgical attempt to correct the gingival recession; 2) long-term (>2 weeks) use of antibiotics in the past 3 months; 3 ) known allergies to the materials used; 4 ) subjects with compromised healing potential; 5) subjects with active infectious diseases (hepatitis, tuberculosis, HIV, etc.); 6) patients taking steroids or medications known to cause gingival enlargement; and 7) pregnant or attempting to become pregnant.

\section{Clinical Parameters}

The following clinical parameters were collected and recorded; all linear measurements were recorded to the nearest $0.5 \mathrm{~mm}$ using a University of North Carolina (UNC) probe: 1) probing depth (PD) was measured at three points on the custom stent (mesio-buccal, mid-buccal, and disto-buccal). The measurement was made from the free gingival margin to the most apical part of the sulcus; 2) clinical attachment level (CAL) was measured at the same reference points used for PD. The measurement was made from the CEJ to the most apical part of the sulcus; 3 ) width of keratinized tissue (WKT) was measured at the midbuccal point from the mucogingival junction (MGJ) to the free gingival margin by a Boley gauge caliper. The MGJ was determined using the rollover technique; 4) $\mathrm{RD}$ was measured by a Boley gauge at the mid-buccal aspect of the tooth. The distance from the stent to the most apical point of free gingival margin was subtracted from the distance from the stent to the CEJ; $5)$ recession width (RW) was measured $1 \mathrm{~mm}$ apical to the CEJ or crown margin in a mesio-distal direction also using a Boley gauge caliper; 6) GT was measured 
at the mid-buccal $2 \mathrm{~mm}$ apical to the free gingival margin by penetrating a UNC probe into the tissue and recorded to the nearest $0.5 \mathrm{~mm} ; 7$ ) plaque index (PI) was recorded according to Silness and Lö ${ }^{55} ; 8$ ) gingival index (GI) was recorded according to Lö $\mathrm{e}^{56}$; 9) wound healing index (WHI) was recorded after surgery using the following criteria: score $1=$ uneventful healing with no gingival edema, erythema, suppuration, patient discomfort, or flap dehiscence; score 2 = uneventful healing with slight gingival edema, erythema, patient discomfort, or flap dehiscence, but no suppuration; and score 3 = poor wound healing with significant gingival edema, erythema, patient discomfort, flap dehiscence, or any suppuration; and 10) the percentage of root coverage (RC) was calculated as ([RD preoperation - RD postoperation]/RD preoperation) $\times 100 \%$.

\section{Data Collection}

Measuring stents for each surgical site were fabricated from self-curing orthodontic acrylic resin. Clinically reproducible measuring points were marked on the stent at the mesio-buccal, mid-buccal, and distobuccal aspects as standardized reference points to assess clinical parameters. Calibration for intraexaminer reliability was performed before, during, and after the study. Two sites in two patients were used for each calibration appointment. Two sets of measurements for each site were recorded at different times within the same day. The intermeasurement interval was 2 hours. The mean kappa value for all parameters was 0.85 prestudy, 0.88 during the study, and 0.90 post-study.

\section{Surgical Protocol}

All procedures were performed under local infiltration of $2 \%$ lidocaine combined with 1:100,000 epinephrine. Sulcular incisions were used on the buccal aspect of the tooth. At papillary areas, the incisions followed the outline of the papilla. The distance between the tip of the papillae and the papillary incision was equivalent to the recession depth. Two vertical releasing incisions were made at the line angles of adjacent teeth and extended into the mucosa. Fullthickness mucoperiosteal flaps were elevated. A releasing incision through the periosteum at the inner aspect of the flap was made to allow coronal flap advancement without tension. Deepithelialization was performed at each papillae to provide a connective tissue bed for flap adaptation. The exposed root surface was thoroughly planed using periodontal curettes, high-speed fine carbide burs, and low-speed fine diamond burs to obtain a smooth and hard surface. Patients in the test group then received PRP over the root surfaces while those in the control group received no further treatment. Flaps were then coronally advanced to cover the exposed root and sutured with a long-lasting suture material. ${ }^{\ddagger}$ A double sling suture was placed at each flap papillae to secure the flap coronally. Interrupted tag sutures were placed at the center of the papillae to facilitate closed adaptation of the flap and underlying connective tissue. Oblique interrupted sutures were placed $45^{\circ}$ toward the coronal direction at the vertical incisions to secure the flap in its new position (Figs. 1 and 2). Gentle pressure was applied at the surgical site with moistened gauze to achieve hemostasis and a close adaptation of the flap to the underlying surface. No surgical dressing materials were used.

\section{PRP Preparation}

Prior to surgery, $30 \mathrm{ml}$ venous blood was drawn from patients randomized to the test group. The blood was then distributed into $10-\mathrm{ml}$ sterilized disposable tubes with $1.5 \mathrm{ml}$ acid citrate dextrose, which functioned as an anticoagulant. The tubes were placed into a general-purpose centrifuge ${ }^{\S}$ for PRP preparation. The techniques used in this study followed the guidelines proposed by Gonshor. ${ }^{41}$ Briefly, after counterbalancing the tubes, the first spin was at 1,300 rpm for 10 minutes. The result was a separation of the whole blood into blood cell and plasma layer. The plasma layer and uppermost part of the cell layer was drawn and placed into $10-\mathrm{ml}$ sterilized tubes that had no anticoagulant. The tubes were then inserted into the centrifuge for a second spin at 2,000 rpm for 10 minutes. The second spin separated PRP at the bottom and clear straw-colored serum at the top. The serum was removed. The PRP layer was then expressed into a sterile container and prepared for use. The clot initiator was a mixture of $5 \mathrm{ml} 10 \%$ calcium chloride $\left(\mathrm{CaCl}_{2}\right)$ and 5,000 $U$ bovine thrombin. The protocol of PRP activation was adding $\mathrm{CaCl}_{2} /$ thrombin in a 10:1 ratio. After a few seconds, the activated PRP gel was applied to the test sites as a coating membrane.

\section{Platelet Count}

Platelet counting was performed to compare the number of platelets in whole blood and PRP. Platelet levels were determined by a hematology analyzer. Three milliliters of whole blood was drawn in an anticoagulant-coated tube. Due to the counting limitation of the machine $(1,000,000$ platelets/ $\mu \mathrm{l})$, PRP samples required for a platelet count were diluted with phosphate buffered saline in a 1:9 ratio.

\section{Postoperative Care}

Analgesics (non-steroidal anti-inflammatory drugs [NSAIDs]) were prescribed to control postoperative discomfort. No antibiotics were prescribed. Patients

\footnotetext{
‡5.0 Vicryl, Ethicon, Johnson \& Johnson, Somerville, NJ. $\S$ Maxm, ACE Surgical Supply, Brockton, MA.

II COULTER MAXM, Global Medical Instrumentation, Ramsey, MN.
} 

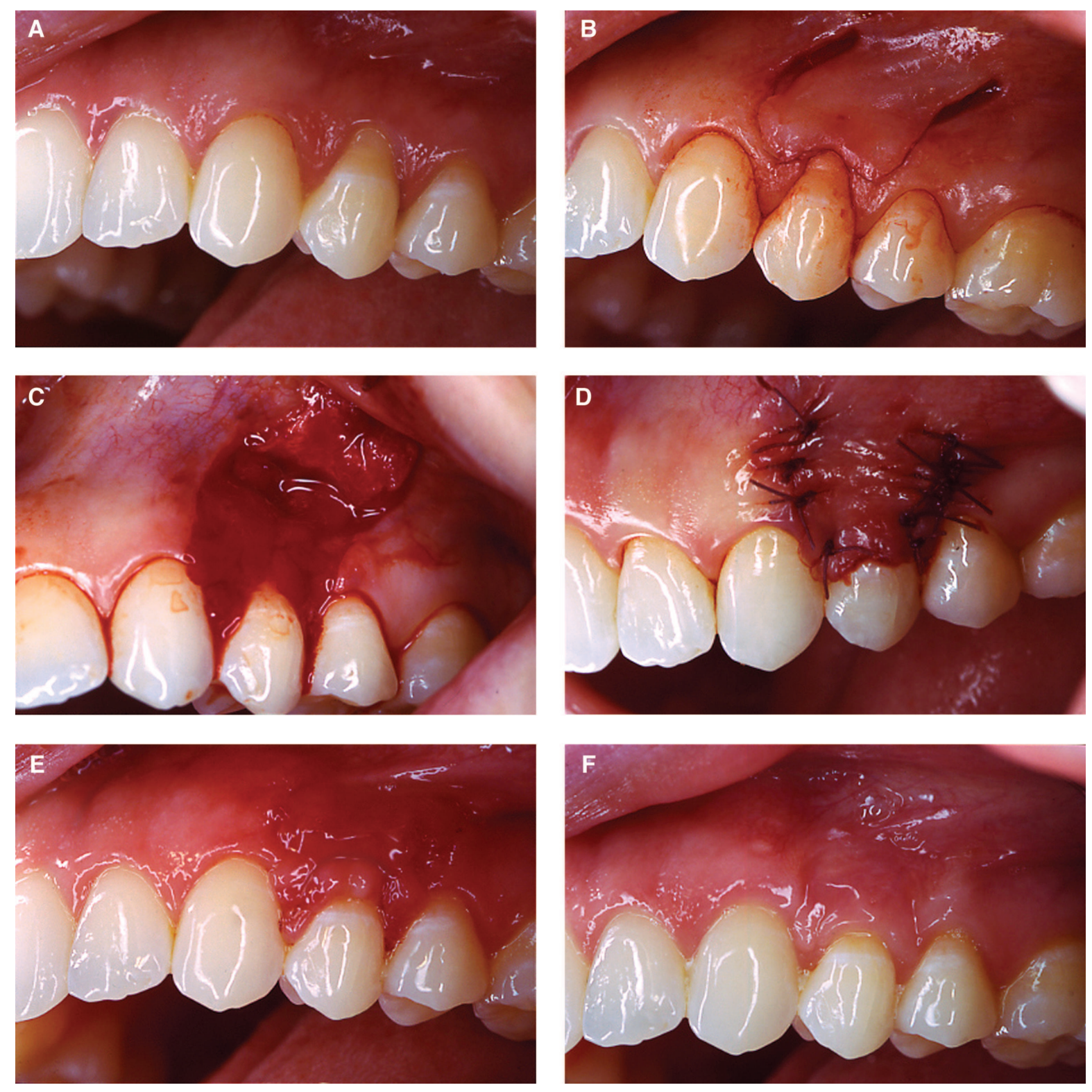

Figure I.

Surgical procedures and results of PRP + CAF. A 26-year-old female patient showed a 2.5-mm recession defect at tooth \# I 2. A) Initial presentation. B) Incisions. C) PRP placed on the root surface. D) Graft is sutured. E) Two-week postoperative follow-up demonstrated WHI = I. F) Six-month follow-up.

were informed not to brush or floss the surgical sites for 3 to 4 weeks. Instead, they were informed to alternate rinsing with salt water and $0.12 \%$ chlorhexidine gluconate rinse for plaque control. Sutures were removed 10 to 14 days after the surgery. Oral hygiene instructions and professional cleaning were provided at each follow-up visit when indicated.

\section{Statistical Analysis}

Data were reported as mean \pm standard deviation. A statistical software program ${ }^{\text {I }}$ was used for data analysis. The Wilcoxon signed rank test was used to analyze parameters before and after treatment within each group. The Mann-Whitney test was used to ana- lyze parameters between test and control groups. All tests were two-sided, and differences were considered statistically significant at $P<0.05$.

\section{RESULTS}

\section{Demographics and Sites}

One patient who had a mandibular premolar site in the test group dropped out of the study after the 1-month follow-up. A total of 23 patients completed the study. The mean age of these patients was $43.8 \pm 11.9$ years ( 24 to 63 years). The mean age in the CAF and PRP + CAF groups was $40.8 \pm 11.5$ years and $47.1 \pm 11.8$

Il SPSS 12, SPSS, Chicago, IL. 

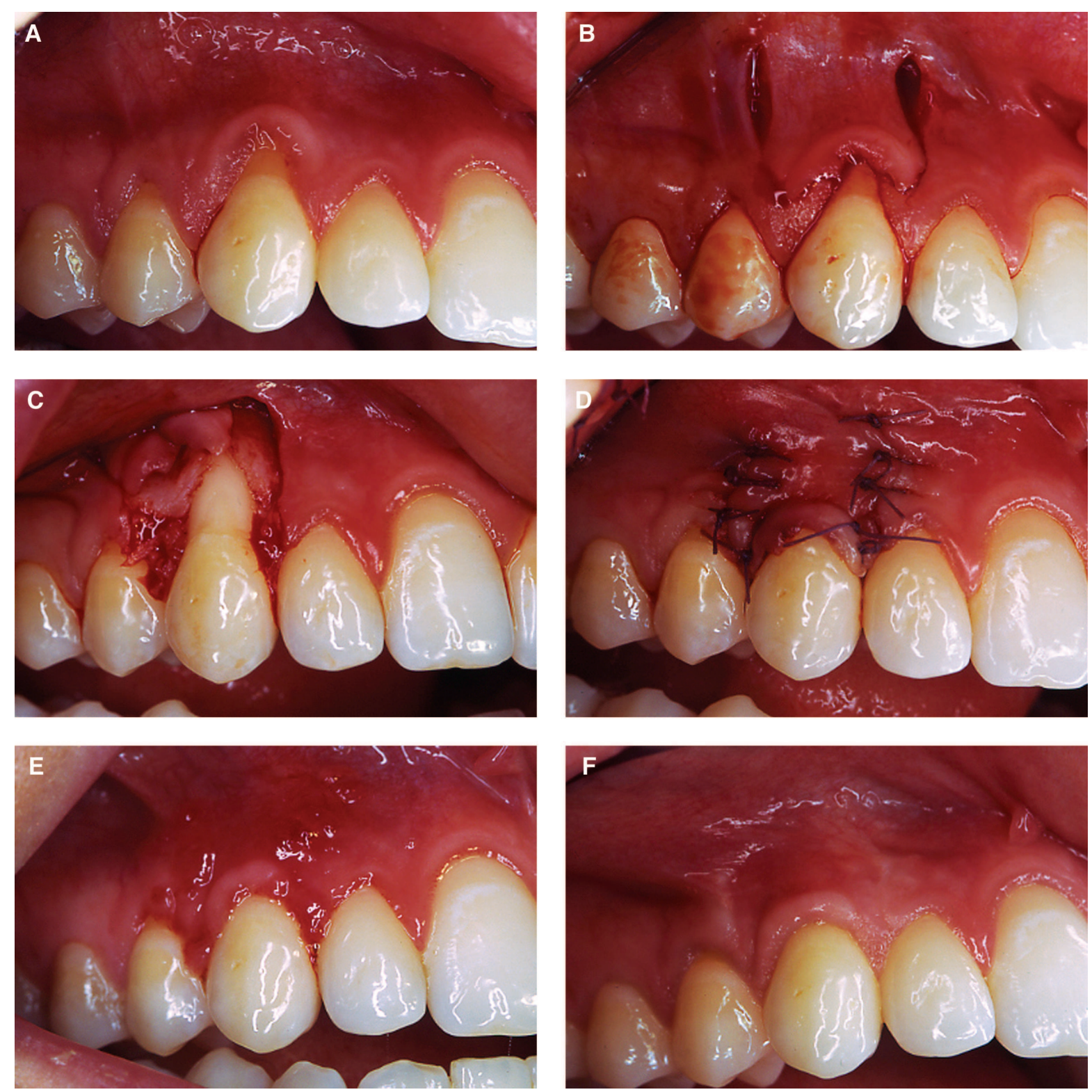

Figure 2.

Surgical procedures and results of CAF. A 24-year-old female patient showed a 2.8-mm recession defect at tooth \#6. A) Initial presentation. B) Incisions. C) Root surface preparation. D) Graft is sutured. E) Two-week postoperative follow-up demonstrated WHI = I. F) Six-month follow-up.

years, respectively $(P>0.05)$. There were 17 females and six males. Nineteen maxillary (11 canines and eight premolars) and four mandibular (two incisors and two premolars) teeth were treated. There were 10 maxillary (six canines and four premolars) and two mandibular (incisor) teeth in the CAF group. In the PRP + CAF group, there were nine maxillary (five canines and four premolars) and two mandibular (premolar) teeth.

\section{Baseline Measurements}

The average initial RD on the control group was $2.9 \pm 0.5 \mathrm{~mm}$ (2.5 to $4 \mathrm{~mm}$ ) and $2.8 \pm 0.2 \mathrm{~mm}$
(2.5 to $3 \mathrm{~mm}$ ) in the PRP + CAF group. The mean $\mathrm{RW}$ of the CAF and PRP + CAF was $3.2 \pm 0.7$ and $3.6 \pm 0.4 \mathrm{~mm}$, respectively. The mean WKT of the CAF and PRP + CAF was $2.7 \pm 1.2$ and $2.7 \pm 1.4$ $\mathrm{mm}$. The average baseline GT of CAF and PRP + CAF was $1.1 \pm 0.4$ and $1.1 \pm 0.2 \mathrm{~mm}$. None of these baseline clinical parameters showed statistically significant differences between the groups $(P>0.05$; Table 1).

\section{Platelet Count}

The mean platelet count in whole blood was $235.3 \pm$ $38.6 \times 10^{3} / \mu \mathrm{l}\left(149\right.$ to $\left.308 \times 10^{3} / \mu \mathrm{l}\right)$. The mean platelet 
Table I.

\section{Baseline Clinical Parameters and Comparisons Between Groups}

\begin{tabular}{|c|c|c|c|c|}
\hline Parameter & Site & $\begin{array}{c}\text { CAF } \\
(n=12)\end{array}$ & $\begin{array}{c}\mathrm{PRP}+\mathrm{CAF} \\
(\mathrm{n}=1 \mathrm{I})\end{array}$ & $P$ Value* \\
\hline $\mathrm{RD}(\mathrm{mm})$ & & $2.9 \pm 0.5$ & $2.8 \pm 0.2$ & NS \\
\hline $\mathrm{RW}(\mathrm{mm})$ & & $3.2 \pm 0.7$ & $3.6 \pm 0.4$ & NS \\
\hline WKT (mm) & & $2.7 \pm 1.2$ & $2.7 \pm 1.4$ & NS \\
\hline GT (mm) & & I. $1 \pm 0.4$ & $1.1 \pm 0.2$ & NS \\
\hline PD (mm) & $\begin{array}{l}\text { Mesio-buccal } \\
\text { Mid-buccal } \\
\text { Disto-buccal }\end{array}$ & $\begin{array}{l}2.8 \pm 0.6 \\
1.8 \pm 0.9 \\
2.7 \pm 0.8\end{array}$ & $\begin{array}{l}2.5 \pm 0.5 \\
1.6 \pm 0.7 \\
2.7 \pm 0.5\end{array}$ & $\begin{array}{l}\text { NS } \\
\text { NS } \\
\text { NS }\end{array}$ \\
\hline $\mathrm{CAL}(\mathrm{mm})$ & $\begin{array}{l}\text { Mesio-buccal } \\
\text { Mid-buccal } \\
\text { Disto-buccal }\end{array}$ & $\begin{array}{l}1.7 \pm 0.5 \\
4.7 \pm 0.8 \\
1.8 \pm 0.6\end{array}$ & $\begin{array}{l}1.8 \pm 0.7 \\
4.3 \pm 0.7 \\
1.9 \pm 1.0\end{array}$ & $\begin{array}{l}\text { NS } \\
\text { NS } \\
\text { NS }\end{array}$ \\
\hline $\mathrm{Pl}$ & $\begin{array}{l}\text { Mesio-buccal } \\
\text { Mid-buccal } \\
\text { Disto-buccal }\end{array}$ & $\begin{array}{l}0.6 \pm 0.9 \\
0.8 \pm 0.9 \\
1.0 \pm 0.9\end{array}$ & $\begin{array}{l}0.5 \pm 0.7 \\
0.9 \pm 0.8 \\
0.8 \pm 0.6\end{array}$ & $\begin{array}{l}\text { NS } \\
\text { NS } \\
\text { NS }\end{array}$ \\
\hline GI & $\begin{array}{l}\text { Mesio-buccal } \\
\text { Mid-buccal } \\
\text { Disto-buccal }\end{array}$ & $\begin{array}{l}0.3 \pm 0.6 \\
0.7 \pm 0.7 \\
0.4 \pm 0.8\end{array}$ & $\begin{array}{l}0.3 \pm 0.7 \\
0.8 \pm 0.8 \\
0.4 \pm 0.7\end{array}$ & $\begin{array}{l}\text { NS } \\
\text { NS } \\
\text { NS }\end{array}$ \\
\hline
\end{tabular}

* $P$ value based on the Mann-Whitney test.

NS = not statistically significant.

count in PRP was $4,085.8 \pm 2,420.6 \times 10^{3} / \mu \mathrm{l}(580$ to $\left.9,180 \times 10^{3} / \mu \mathrm{l}\right)$. The average increase of platelet concentration in PRP compared to whole blood was 17.5 times (2.5 to 40.6 times). The mean PRP production per $10 \mathrm{ml}$ whole blood was $0.3 \mathrm{ml}$. The mean platelet recovery from whole blood was $57.9 \%$.

\section{Intragroup Comparisons}

The reduction of RD and RW 6 months after surgery was statistically significant compared to the baseline $(P<0.05)$ in both groups (Table 2$)$. The gain of CAL and $\mathrm{RC}$ was also significant at 3 and 6 months in both groups $(P<0.05)$. The corresponding root coverage achieved to PRP concentration is presented in Table 3 . The mean platelet number of PRP in cases associated with complete root coverage was 3,767.1 \pm $2,876.4 \times 10^{3} / \mu \mathrm{l}\left(580\right.$ to $\left.9,180 \times 10^{3} / \mu \mathrm{l}\right)$. In the CAF group, the $0.6 \mathrm{~mm}$ gain of WKT was significant after 6 months $(P<0.05$; Table 2$)$. A $0.3-\mathrm{mm}$ increase of GT was observed in the CAF group after 6 months, while the PRP + CAF group demonstrated a $0.6 \mathrm{~mm}$ gain in GT $(P<0.05$; Table 2$)$. The WHI at 2 weeks was $1.3 \pm 0.5$ in the CAF group and $1.2 \pm 0.4$ in the PRP + CAF group; both groups returned to 1 after 1 month. The GI at 2 weeks and 1 month after surgery increased significantly in both groups but returned
Table 2.

\section{Intragroup Comparisons}

\begin{tabular}{|c|c|c|c|}
\hline Variables & Groups & Mean \pm SD & P Value* \\
\hline \multirow[t]{2}{*}{$\mathrm{RC}(\%)$} & CAF & $83.5 \pm 21.8$ & $0.002^{\dagger}$ \\
\hline & $\mathrm{PRP}+\mathrm{CAF}$ & $81.0 \pm 28.7$ & $0.003^{\dagger}$ \\
\hline \multirow[t]{2}{*}{$\mathrm{RD}(\mathrm{mm})$} & CAF & $-2.5 \pm 0.8$ & $0.002^{\dagger}$ \\
\hline & $\mathrm{PRP}+\mathrm{CAF}$ & $-2.3 \pm 0.9$ & $0.003^{\dagger}$ \\
\hline \multirow[t]{2}{*}{$\mathrm{RW}(\mathrm{mm})$} & CAF & $-2.9 \pm 1.0$ & $0.002^{\dagger}$ \\
\hline & $\mathrm{PRP}+\mathrm{CAF}$ & $-3.1 \pm 1.0$ & $0.003^{\dagger}$ \\
\hline \multirow[t]{2}{*}{$\mathrm{CAL}(\mathrm{B})(\mathrm{mm})$} & CAF & $-3.0 \pm 1.4$ & $0.002^{\dagger}$ \\
\hline & $\mathrm{PRP}+\mathrm{CAF}$ & $-2.5 \pm 1.4$ & $0.003^{\dagger}$ \\
\hline \multirow[t]{2}{*}{ WKT (mm) } & CAF & $0.6 \pm 0.7$ & $0.025^{\dagger}$ \\
\hline & $\mathrm{PRP}+\mathrm{CAF}$ & $0.3 \pm 0.9$ & NS \\
\hline \multirow[t]{2}{*}{ GT (mm) } & CAF & $0.3 \pm 0.4$ & NS \\
\hline & $\mathrm{PRP}+\mathrm{CAF}$ & $0.6 \pm 0.4$ & $0.007^{\dagger}$ \\
\hline
\end{tabular}

* $P$ value was based on the Wilcoxon signed rank test.

$\dagger$ Statistical significance between baseline and 6 months $(P<0.05)$. NS = not statistically significant.

to baseline after 3 months. PI increased 2 weeks after the treatment and gradually returned to the baseline in both groups. The measurements of PD remained consistent throughout the study. There was an outlier, RC $20 \%$, in the PRP + CAF group. The characteristics of this case were mandibular first premolar, thin gingival tissue $(1 \mathrm{~mm})$, and shallow vestibule. The platelet concentration in this patient's whole blood was $288 \times 10^{3} /$ $\mu l$ and $5,884 \times 10^{3} / \mu l$ in PRP, producing a 20.4 ratio. Even though minimal root coverage was accomplished, the WKT increased to $2 \mathrm{~mm}$. No further treatment was provided upon the patient's request.

\section{Intergroup Comparisons}

At 3 months, the mean RC for CAF group was $88.1 \% \pm$ $16.9 \%$ (58.6\% to $100 \%)$ and the PRP + CAF group was $81.8 \% \pm 27.7 \%$ ( $12 \%$ to $100 \%$ ). At the 6 -month followup, the mean RC of the CAF group was $83.5 \% \pm 21.8 \%$ ( $48.3 \%$ to $100 \%$ ) and the PRP + CAF group was $81.0 \%$ $\pm 28.7 \%$ (20\% to $100 \%$ ). After elimination of the outlier in the PRP + CAF group, the RC at 3 and 6 months was $88.8 \pm 16.1 \%(60 \%$ to $100 \%)$ and $87.1 \% \pm 21.4 \%$ ( $44.4 \%$ to $100 \%)$, respectively. The comparisons of $\mathrm{RC}$ between the groups showed no statistically significant difference $(P>0.05)$. Overall, 14 out of 23 patients $(60.9 \%)$ achieved complete root coverage. Seven out of 12 patients $(58.3 \%)$ in the CAF group achieved $100 \%$ root coverage. For the PRP + CAF group, seven out of 11 patients (63.6\%) showed $100 \%$ root coverage. The RD at 6 months was $0.5 \pm$ 
Table 3.

\section{Correlation Between Platelet Concentration and Percentage of Root Coverage at 6 Months}

\begin{tabular}{ccccccc}
\hline $\begin{array}{l}\text { Test } \\
\text { Group }\end{array}$ & $\begin{array}{c}\text { Whole Blood } \\
\left(\left|0^{3} / \mu\right|\right)\end{array}$ & $\begin{array}{c}\text { PRP } \\
\left(\left|0^{3} / \mu\right|\right)\end{array}$ & Ratio & $\%$ RC & Tooth \# \\
\hline 1 & 226 & 9,180 & 40.6 & 100 & 6 \\
2 & 256 & 3,070 & 12.0 & 100 & 6 \\
3 & 215 & 3,280 & 15.3 & 100 & 11 \\
4 & 224 & 1,060 & 4.7 & 100 & 11 \\
5 & 232 & 580 & 2.5 & 100 & 11 \\
6 & 272 & 4,500 & 16.5 & 60 & 12 \\
7 & 220 & 6,640 & 30.2 & 66.7 & 12 \\
8 & 216 & 3,990 & 18.5 & 100 & 12 \\
9 & 248 & 5,210 & 21.0 & 100 & 12 \\
10 & 308 & 3,520 & 11.4 & 44.4 & 20 \\
\hline 1 & 257 & 5,880 & 22.9 & 20 & 28 \\
\hline
\end{tabular}

$0.6 \mathrm{~mm}$ in the CAF group and $0.5 \pm 0.7 \mathrm{~mm}$ in the PRP + CAF group $(P>0.05)$. Without the outlier in the PRP + CAF group, the RD decreased to $0.4 \pm 0.6 \mathrm{~mm}$, still showing no differences between the groups. Other clinical parameters, such as RW, WKT, GT, PD, CAL, PI, and WHI, also showed insignificant differences between the groups (Table 4 ).

\section{DISCUSSION}

PRP has been shown to enhance soft tissue healing, promote initial stabilization, and revascularization of the flaps and grafts in root coverage procedures. ${ }^{29}$ However, limited evidence is currently available verifying these claims. Therefore, this pilot study was designed to investigate the effects of PRP on CAF root coverage procedure.

The technique to produce PRP was introduced by Gonshor. ${ }^{41}$ According to this report, the technique is able to produce a platelet concentration eight times greater than whole blood. The volume of PRP produced was $0.85 \mathrm{ml}$ from $8.5 \mathrm{ml}$ blood, and the mean platelet recovery was $67.5 \%$. The concentration of TGF- $\beta 1$ and PDGF-AB in PRP was, respectively, 14.5 and 11 times more than the whole blood. ${ }^{41}$ In our study, the average increase of platelet concentration in PRP was 17.5 times (2.5 to 40.6 times) compared to baseline. The only sample that showed less than $1,000 \times 10^{3} / \mu$ l platelets was the very first one, suggesting that this technique is sensitive and re-
Table 4.

\section{Intergroup Comparisons}

\begin{tabular}{|c|c|c|c|}
\hline Parameters & CAF & $\mathrm{PRP}+\mathrm{CAF}$ & P Value* \\
\hline \multirow[t]{2}{*}{$\mathrm{RC}(\%) 6$ months } & $83.5 \pm 21.8$ & $\begin{array}{l}81.0 \pm 28.7 \\
\quad \text { (with outlier) }\end{array}$ & NS \\
\hline & & $\begin{array}{l}87.1 \pm 21.4 \\
\quad \text { (without outlier) }\end{array}$ & NS \\
\hline \multirow[t]{2}{*}{ RD (mm) 6 months } & $0.5 \pm 0.6$ & $\begin{array}{l}0.5 \pm 0.7 \\
\quad \text { (with outlier) }\end{array}$ & NS \\
\hline & & $\begin{array}{l}0.4 \pm 0.6 \\
\quad \text { (without outlier) }\end{array}$ & NS \\
\hline \multirow[t]{2}{*}{ RW (mm) 6 months } & $0.3 \pm 0.8$ & $\begin{array}{l}0.6 \pm 1.1 \\
\quad \text { (with outlier) }\end{array}$ & NS \\
\hline & & $\begin{array}{l}0.4 \pm 1.0 \\
\quad \text { (without outlier) }\end{array}$ & NS \\
\hline WKT (mm) 6 months & $3.2 \pm 1.0$ & $3.1 \pm 0.7$ & NS \\
\hline GT (mm) 6 months & $1.4 \pm 0.4$ & $1.7 \pm 0.5$ & NS \\
\hline WHI 2 weeks & $1.3 \pm 0.5$ & $1.2 \pm 0.4$ & NS \\
\hline $\begin{array}{l}\text { Gl (mesio-buccal) } \\
3 \text { months }\end{array}$ & $0.8 \pm 0.6$ & $0.2 \pm 0.4$ & $0.044^{\dagger}$ \\
\hline
\end{tabular}

Data are presented as mean \pm standard deviation.

* $P$ value based on the non-parametric Mann-Whitney test.

+ Statistical significance between test and control groups $(P<0.05)$.

NS $=$ not statistically significant.

quires a learning curve. The average PRP production per $10 \mathrm{ml}$ whole blood was $0.3 \mathrm{ml}$. This was lower than the previous report. However, this small volume of PRP contributed to the increased platelet concentration comparing to other studies. ${ }^{34,41}$ The mean platelet recovery from whole blood was $57.9 \%$, which was lower than Gonshor's result. This might be explained by the small volume of PRP procured from whole blood. Recent advances in PRP technology are able to provide more consistent platelet concentrations than those observed in this study. However, despite the small sample size observed, no dose-dependent effect of PRP on soft tissue wound healing could be detected.

No statistically significant differences were noted between groups, suggesting that both procedures are comparable to treat Miller's Class I recession defects. The mean RC at 6 months was $83.5 \% \pm 21.8 \%$ in CAF and $81.0 \% \pm 28.7 \%$ in PRP + CAF. Complete root coverage was achieved in $58.3 \%$ of CAF treated sites and $63.6 \%$ of PRP + CAF sites. These results were in agreement with others. ${ }^{17,57-59}$ Results from these studies indicated that CAF is a predictable root coverage procedure. The application of PRP showed no additional benefit to enhance outcomes achieved by CAF alone. This may be partly due to the favorable re- 
sults obtained in both groups, small sample size, and defects (Miller's Class I) known to experience predictable root coverage. Future investigations including larger sample sizes and more challenging recession defects should be considered.

The effects of PRP on early soft tissue healing were analyzed by clinical evaluation. The indices used were GI and WHI, which were developed to evaluate the gingival appearance (i.e., erythema and edema). The PRP + CAF group had a lower WHI 2 weeks after surgery than CAF alone. However, because of the small sample size, the difference was not statistically significant. Nonetheless, the WHI reached a plateau 1 month after surgery in both groups suggesting uneventful healing regardless of the PRP application. PDGF and VEGF, the main autologous growth factors of PRP, are associated with pericytes and capillary formation, respectively, and serve as potent angiogenic factors. ${ }^{60-62}$ These growth factors might enhance soft tissue healing by increasing the angiogenesis and matrix biosynthesis during early wound healing. A recent report in an ex vivo model of gingival repair showed that sustained PDGF delivery promotes wound closure. ${ }^{63}$ The results from this study showed the trend of accelerated soft tissue healing in the PRP group, which was confirmed by clinical visual investigation. However, this short-term benefit did not influence the final clinical outcomes, e.g., percentage of root coverage. In addition, PDGF, TGF- $\beta$, and IGF-I found in PRP have been demonstrated to regenerate new bone and cementum. ${ }^{64-67}$ Histological studies have demonstrated that the dentogingival junction after CAF surgery was established by reformation of epithelial and connective tissue attachment with minimal bone repair. ${ }^{20,21}$ Nevertheless, no histological examination was performed in the present study. Hence, the effect of PRP on the overall regeneration capacity remains to be determined. Further studies in this field are needed.

Six months after surgery, the PRP + CAF group gained $0.4 \mathrm{~mm}$ GT above that of CAF alone. Although this increase was not statistically significant $(P=0.1)$, based on our data, if the sample size was increased to 27 subjects in each group, we would be able to detect a $0.35-\mathrm{mm}$ difference between the groups at $\alpha=0.05$ with $80 \%$ power.

The threshold of platelet concentration and its correlation to $\mathrm{RC}$ was difficult to designate in this study. In the PRP + CAF group, the mean platelet concentration of PRP in those achieving $100 \%$ root coverage was $3,767.1 \pm 2,876.4 \times 10^{3} / \mu l$ with a wide range from 580 to $9,180 \times 10^{3} / \mu \mathrm{l}$. In cases that did not achieve complete root coverage, the average platelet concentration of PRP was higher $\left(5,135.0 \pm 1,394.2 \times 10^{3} /\right.$ $\mu \mathrm{l})$. The platelet concentrations in PRP have been shown to have individual variability. ${ }^{40,41}$ Preparation techniques also contribute to the variation. ${ }^{40} \mathrm{How}$ ever, patient age and gender do not appear to be crucial factors. ${ }^{35,39}$ Recently, one animal study found that the platelet concentration in PRP was important to determine its biological effect. With intermediate platelet concentration, approximately $1,000 \times 10^{3} /$ $\mu \mathrm{l}$, more bone regeneration was observed. ${ }^{68}$ Although growth factor levels of PRP were not measured in this study, previous reports failed to show that the growth factor content correlated with the platelet concentration in the whole blood and the PRP. ${ }^{35,41}$ Hence, there is no strong evidence to support the relationship between the platelet concentration and wound healing enhancement. Despite the small sample size in this study, no dose-response relationship was observed between platelet concentration and root coverage.

This pilot study indicates that CAF is a predictable approach to treat Miller's Class I gingival recession. The additional application of PRP failed to improve root coverage after CAF in Miller's Class I recession defects. However, a positive trend of PRP utilization was observed since lower GI and WHI values as well as increased GT postoperatively were observed in this group. It is important to emphasize that this positive trend should be better observed and confirmed in studies involving a larger number of subjects. The lack of difference between groups could also lead to different outcomes in a larger sample size. Therefore, future studies with larger sample sizes are recommended to further explore this hypothesis.

\section{ACKNOWLEDGMENTS}

The authors thank Drs. Orasa Anusaksathien (Department of Periodontics/Prevention/Geriatrics, University of Michigan, School of Dentistry), Ho-Young Byun (Department of Periodontics/Prevention/Geriatrics, University of Michigan, School of Dentistry), Stephan E. Feinberg (Oral and Maxillofacial Department, University of Michigan, School of Dentistry), and Brady West (Center for Statistical Consult and Research, University of Michigan) for their assistance in this project. This study was supported by the University of Michigan Periodontal Graduate Student Research Fund and the 2003 Dental Master's Thesis Award Program from the Delta Dental Fund, Okemos, Michigan.

\section{REFERENCES}

1. American Academy of Periodontology. Glossary of Periodontal Terms, 4th ed. Chicago, IL: American Academy of Periodontology; 2001:44.

2. Albandar JM, Kingman A. Gingival recession, gingival bleeding, and dental calculus in adults 30 years of age and older in the united states, 1988-1994. J Periodontol 1999;70:30-43. 
3. Löe H, Anerud A, Boysen H. The natural history of periodontal disease in man: Prevalence, severity, and extent of gingival recession. J Periodontol 1992;63: 489-495.

4. Arowojolu MO. Gingival recession at the University College Hospital, Ibadan - Prevalence and effect of some aetiological factors. Afr J Med Med Sci 2000; 29:259-263.

5. Thomson WM, Hashim R, Pack AR. The prevalence and intraoral distribution of periodontal attachment loss in a birth cohort of 26-year-olds. J Periodontol 2000;71:1840-1845

6. Rees JS, Addy M. A cross-sectional study of dentine hypersensitivity. J Clin Periodontol 2002;29:997-1003.

7. Goutoudi P, Koidis PT, Konstantinidis A. Gingival recession: A cross-sectional clinical investigation. Eur J Prosthodont Restor Dent 1997;5:57-61.

8. Oliver RC, Brown LJ, Löe H. Periodontal diseases in the United States population. J Periodontol 1998;69: 269-278.

9. Grupe H, Warren RJ. Repair of gingival defects by a sliding flap operation. J Periodontol 1956;27:290-295.

10. Cohen DW, Ross SE. The double papillae repositioned flap in periodontal therapy. J Periodontol 1968;39: 65-70.

11. Harvey PM. Management of advanced periodontitis. I. Preliminary report of a method of surgical reconstruction. N Z Dent J 1965;61:180-187.

12. Tarnow DP. Semilunar coronally repositioned flap. $J$ Clin Periodontol 1986;13:182-185.

13. Bjorn $H$. Free transplantation of gingiva propria. [Abstract]. Sueriges Tandlak Tidskr 1963;22:684.

14. Langer B, Langer L. Subepithelial connective tissue graft technique for root coverage. J Periodontol 1985; 56:715-720.

15. Cortellini P, Pini Prato GP, DeSanctis M, Baldi C, Clauser $C$. Guided tissue regeneration procedure in the treatment of a bone dehiscence associated with a gingival recession: A case report. Int $J$ Periodontics Restorative Dent 1991;11:460-467.

16. Sumner CF 3rd. Surgical repair of recession on the maxillary cuspid: Incisally repositioning the gingival tissues. J Periodontol 1969;40:119-121.

17. Pini Prato G, Baldi C, Pagliaro $U$, et al. Coronally advanced flap procedure for root coverage. Treatment of root surface: Root planing versus polishing. J Periodontol 1999;70:1064-1076.

18. Wennstrom JL. Mucogingival therapy. Ann Periodontol 1996;1:671-701.

19. Greenwell H, Bissada NF, Henderson RD, Dodge JR. The deceptive nature of root coverage results. J Periodontol 2000;71:1327-1337.

20. Gottlow J, Nyman S, Karring T, Lindhe J. Treatment of localized gingival recessions with coronally displaced flaps and citric acid. An experimental study in the dog. $J$ Clin Periodontol 1986;13:57-63.

21. Lee EJ, Meraw SJ, Oh TJ, Giannobile WV, Wang HL. Comparative histologic analysis of coronally advanced flap with and without collagen membrane for root coverage. J Periodontol 2002;73:779-788.

22. Miller PD Jr. Root coverage using the free soft tissue autograft following citric acid application. III. A successful and predictable procedure in areas of deepwide recession. Int $J$ Periodontics Restorative Dent 1985;5:14-37.

23. Harris RJ, Harris AW. The coronally positioned pedicle graft with inlaid margins: A predictable method of obtaining root coverage of shallow defects. Int $J$ Periodontics Restorative Dent 1994;14:228-241.

24. Bouchard P, Nilveus R, Etienne D. Clinical evaluation of tetracycline $\mathrm{HCl}$ conditioning in the treatment of gingival recessions. A comparative study. J Periodontol 1997;68:262-269.

25. Abbas F, Wennstrom J, Van der Weijden F, Schneiders T, Van der Velden U. Surgical treatment of gingival recessions using emdogain gel: Clinical procedure and case reports. Int J Periodontics Restorative Dent 2003; 23:607-613.

26. Ito $\mathrm{K}$, Akutagawa $\mathrm{H}$. Periosteal connective tissue grafting or root coverage with enamel matrix derivative: A case report. J Esthet Restor Dent 2001;13:172178.

27. McGuire MK, Cochran DL. Evaluation of human recession defects treated with coronally advanced flaps and either enamel matrix derivative or connective tissue. Part 2: Histological evaluation. J Periodontol 2003; $74: 1126-1135$.

28. Sallum EA, Casati MZ, Caffesse RG, Funis LP, Nociti Junior FH, Sallum AW. Coronally positioned flap with or without enamel matrix protein derivative for the treatment of gingival recessions. Am J Dent 2003; 16:287-291.

29. Petrungaro PS. Using platelet-rich plasma to accelerate soft tissue maturation in esthetic periodontal surgery. Compend Contin Educ Dent 2001;22:729. $732,734,736$

30. Kawase T, Okuda K, Wolff LF, Yoshie H. Platelet-rich plasma-derived fibrin clot formation stimulates collagen synthesis in periodontal ligament and osteoblastic cells in vitro. J Periodontol 2003;74:858-864.

31. Anitua E. Plasma rich in growth factors: Preliminary results of use in the preparation of future sites for implants. Int $J$ Oral Maxillofac Implants 1999;14: 529-535.

32. Kiuru J, Viinikka L, Myllyla G, Pesonen K, Perheentupa J. Cytoskeleton-dependent release of human platelet epidermal growth factor. Life Sci 1991;49:1997-2003.

33. Maloney JP, Silliman CC, Ambruso DR, Wang J, Tuder RM, Voelkel NF. In vitro release of vascular endothelial growth factor during platelet aggregation. Am J Physiol 1998;275:H1054-H1061.

34. Marx RE, Carlson ER, Eichstaedt RM, Schimmele SR, Strauss JE, Georgeff KR. Platelet-rich plasma: Growth factor enhancement for bone grafts. Oral Surg Oral Med Oral Pathol Oral Radiol Endod 1998;85: 638-646.

35. Weibrich G, Kleis WK, Hafner G, Hitzler WE. Growth factor levels in platelet-rich plasma and correlations with donor age, sex, and platelet count. J Craniomaxillofac Surg 2002;30:97-102.

36. Okuda K, Kawase T, Momose $M$, et al. Platelet-rich plasma contains high levels of platelet-derived growth factor and transforming growth factor-beta and modulates the proliferation of periodontally related cells in vitro. J Periodontol 2003;74:849-857.

37. Lacoste E, Martineau I, Gagnon G. Platelet concentrates: Effects of calcium and thrombin on endothelial cell proliferation and growth factor release. $J$ Periodontol 2003;74:1498-1507.

38. Marx RE. Platelet-rich plasma (PRP): What is PRP and what is not PRP? Implant Dent 2001;10:225-228.

39. Weibrich G, Kleis WK, Kunz-Kostomanolakis M, Loos $\mathrm{AH}$, Wagner W. Correlation of platelet concentration in platelet-rich plasma to the extraction method, age, 
sex, and platelet count of the donor. Int $J$ Oral Maxillofac Implants 2001;16:693-699.

40. Weibrich G, Kleis WK. Curasan PRP kit vs. PCCS PRP system. Collection efficiency and platelet counts of two different methods for the preparation of plateletrich plasma. Clin Oral Implants Res 2002;13:437-443.

41. Gonshor A. Technique for producing platelet-rich plasma and platelet concentrate: Background and process. Int J Periodontics Restorative Dent 2002;22: 547-557.

42. Kovacs K, Velich N, Huszar T, et al. Comparative study of beta-tricalcium phosphate mixed with platelet-rich plasma versus beta-tricalcium phosphate, a bone substitute material in dentistry. Acta Vet Hung 2003;51:475-484.

43. Fennis JP, Stoelinga PJ, Jansen JA. Mandibular reconstruction: A histological and histomorphometric study on the use of autogenous scaffolds, particulate cortico-cancellous bone grafts and platelet rich plasma in goats. Int J Oral Maxillofac Surg 2004;33: 48-55.

44. Zechner W, Tangl S, Tepper G, et al. Influence of platelet-rich plasma on osseous healing of dental implants: A histologic and histomorphometric study in minipigs. Int $J$ Oral Maxillofac Implants 2003;18: 15-22.

45. Kim SG, Kim WK, Park JC, Kim HJ. A comparative study of osseointegration of avana implants in a demineralized freeze-dried bone alone or with platelet-rich plasma. J Oral Maxillofac Surg 2002;60:1018-1025.

46. Fuerst G, Gruber R, Tangl S, Sanroman F, Watzek G. Enhanced bone-to-implant contact by plateletreleased growth factors in mandibular cortical bone: A histomorphometric study in minipigs. Int $J$ Oral Maxillofac Implants 2003;18:685-690.

47. Fontana S, Olmedo DG, Linares JA, Guglielmotti MB, Crosa ME. Effect of platelet-rich plasma on the periimplant bone response: An experimental study. Implant Dent 2004;13:73-78.

48. Kassolis JD, Rosen PS, Reynolds MA. Alveolar ridge and sinus augmentation utilizing platelet-rich plasma in combination with freeze-dried bone allograft: Case series. J Periodontol 2000;71:1654-1661.

49. Wiltfang J, Schlegel KA, Schultze-Mosgau S, Nkenke E, Zimmermann R, Kessler P. Sinus floor augmentation with beta-tricalciumphosphate (beta-TCP): Does platelet-rich plasma promote its osseous integration and degradation? Clin Oral Implants Res 2003;14: 213-218.

50. Rodriguez A, Anastassov GE, Lee H, Buchbinder D, Wettan H. Maxillary sinus augmentation with deproteinated bovine bone and platelet rich plasma with simultaneous insertion of endosseous implants. J Oral Maxillofac Surg 2003;61:157-163.

51. Maiorana C, Sommariva L, Brivio P, Sigurta D, Santoro $F$. Maxillary sinus augmentation with anorganic bovine bone (Bio-Oss) and autologous platelet-rich plasma: Preliminary clinical and histologic evaluations. Int $J$ Periodontics Restorative Dent 2003;23:227-235.

52. Mazor Z, Peleg M, Garg AK, Luboshitz J. Platelet-rich plasma for bone graft enhancement in sinus floor augmentation with simultaneous implant placement: Patient series study. Implant Dent 2004;13:65-72.

53. O'Leary TJ, Drake RB, Naylor JE. The plaque control record. J Periodontol 1972;43:38.

54. Miller PD Jr. A classification of marginal tissue recession. Int J Periodontics Restorative Dent 1985;5:8-13.
55. Silness J, Löe H. Periodontal disease in pregnancy. II. Correlation between oral hygiene and periodontal condtion. Acta Odontol Scand 1964;22:121-135.

56. Löe $H$. The gingival index, the plaque index and the retention index systems. JPeriodontol 1967;38:610-616.

57. Pini Prato G, Pagliaro U, Baldi C, et al. Coronally advanced flap procedure for root coverage. Flap with tension versus flap without tension: A randomized controlled clinical study. J Periodontol 2000;71:188201.

58. Hagewald S, Spahr A, Rompola E, Haller B, Heijl L, Bernimoulin JP. Comparative study of emdogain and coronally advanced flap technique in the treatment of human gingival recessions. A prospective controlled clinical study. J Clin Periodontol 2002;29:35-41.

59. Modica F, Del Pizzo M, Roccuzzo M, Romagnoli R. Coronally advanced flap for the treatment of buccal gingival recessions with and without enamel matrix derivative. A split-mouth study. J Periodontol 2000; 71:1693-1698.

60. Sato N, Beitz JG, Kato J, et al. Platelet-derived growth factor indirectly stimulates angiogenesis in vitro. Am J Pathol 1993;142:1119-1130.

61. Risau W, Drexler H, Mironov V, et al. Platelet-derived growth factor is angiogenic in vivo. Growth Factors 1992;7:261-266.

62. Leung DW, Cachianes G, Kuang WJ, Goeddel DV, Ferrara N. Vascular endothelial growth factor is a secreted angiogenic mitogen. Science 1989;246:13061309.

63. Anusaksathien O, Webb SA, Jin QM, Giannobile WV. Platelet-derived growth factor gene delivery stimulates ex vivo gingival repair. Tissue Eng 2003;9:745-756.

64. Howell TH, Fiorellini JP, Paquette DW, Offenbacher S, Giannobile WV, Lynch SE. A phase I/II clinical trial to evaluate a combination of recombinant human platelet-derived growth factor-BB and recombinant human insulin-like growth factor-I in patients with periodontal disease. J Periodontol 1997;68:1186-1193.

65. Giannobile WV, Finkelman RD, Lynch SE. Comparison of canine and non-human primate animal models for periodontal regenerative therapy: Results following a single administration of PDGF/IGF-I. J Periodontol 1994;65:1158-1168.

66. Camelo M, Nevins ML, Schenk RK, Lynch SE, Nevins $M$. Periodontal regeneration in human class II furcations using purified recombinant human plateletderived growth factor-BB (rhPDGF-BB) with bone allograft. Int $J$ Periodontics Restorative Dent 2003; 23:213-225.

67. Nevins M, Camelo M, Nevins ML, Schenk RK, Lynch SE. Periodontal regeneration in humans using recombinant human platelet-derived growth factor-BB (rhPDGF-BB) and allogenic bone. J Periodontol 2003; 74:1282-1292.

68. Weibrich G, Hansen T, Kleis W, Buch R, Hitzler WE. Effect of platelet concentration in platelet-rich plasma on peri-implant bone regeneration. Bone 2004;34: 665-671.

Correspondence: Dr. Hom-Lay Wang, Department of Periodontics/Prevention/Geriatrics, University of Michigan, School of Dentistry, 1011 N. University Ave., Ann Arbor, MI 48109. Fax: 734/936-0374; e-mail: homlay@ umich.edu.

Accepted for publication March 12, 2005. 